\title{
Geometry measurement and tool surface evaluation using a focus-variation microscope
}

\author{
Pomiar geometrii i ocena powierzchni narzędzi \\ za pomocą mikroskopu różnicowania ogniskowego
}

\author{
DARIUSZ BRZOZOWSKI \\ MICHAL WIECZOROWSKI \\ BARTOSZ GAPIŃSKI *
}

DOI: https://doi.org/10.17814/mechanik.2017.11.167

Possibility of measuring the geometrical features of cutting tools and surface roughness by means of a focus-variation microscope is presented. This technology supports manufacturers in the development of new products and in the quality control of cutting edges and geometry. All measurements, regardless of the application site, are characterized by high resolution, repeatability and traceability. Furthermore, focus-variation microscopy allows measurement of surface irregularities and edge chipping, giving a wide range of possibilities for numerical analysis of edge quality. The technology also provides the stability of measurement results obtained even under production conditions.

KEYWORDS: cutting tools, focus-variation, chipping measurement, tool roughness

Focal differentiation is a scanning imaging technique used to measure the microstructure and surface roughness [1-4]. It combines functionality of the surface roughness measurement with micro-coordinate measurement. Focal differentiation measurements are reproducible, identifiable, and produce results with the vertical resolution of $10 \mathrm{~nm}$. By using this technique, it is possible to analyze a surface with a very different reflectivity and those having inclination of slopes of up to $87^{\circ}$.

\section{Focal differentiation technique}

The focal differentiation measurement technology is reflected in the norm EN ISO 25178. It combines the low focusing depth of the optical system and image scanning in the vertical direction to produce a color image of the surface [5]. An example of a sample microscope, used for testing the cutting tools, is shown in fig. 1.

\footnotetext{
* Mgr inż. Dariusz Brzozowski (db@ita-polska.com.pl) - ITA sp. z o.o., sp.k.; prof. dr hab. inż. Michał Wieczorowski (michal.wieczorowski@put. poznan.pl), dr inż. Bartosz Gapiński (bartosz.gapinski@put.poznan.pl) Zakład Metrologii i Systemów Pomiarowych Politechniki Poznańskiej
}

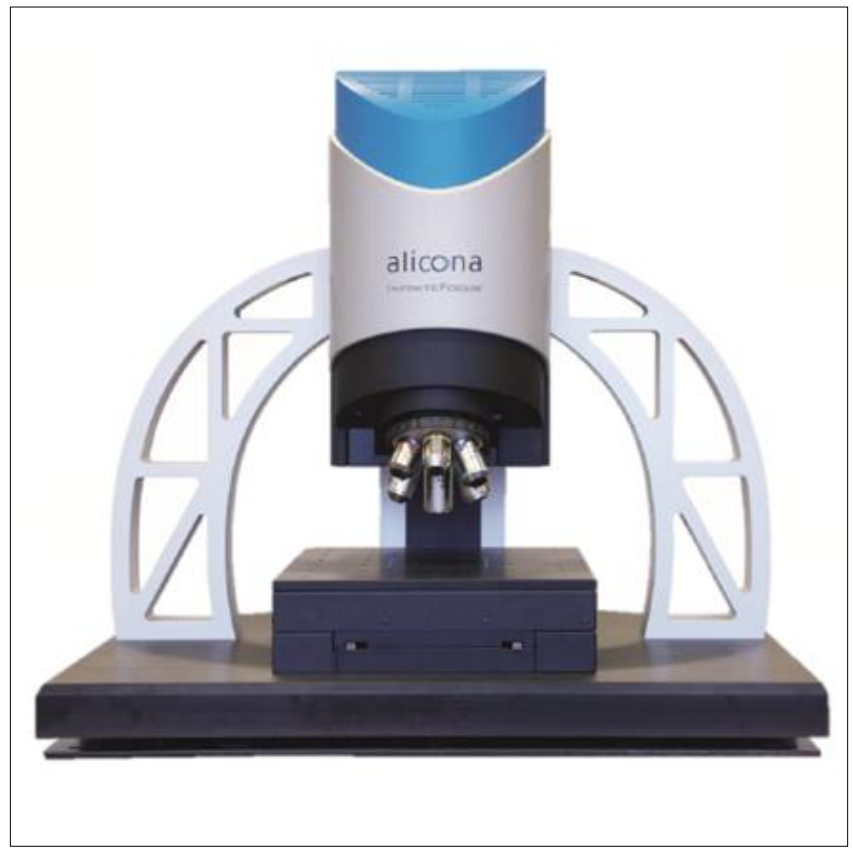

Fig. 1. Focal differentiation microscope (Alicona IF G5)

The essential element of the measurement system is precision optics, which incorporates a variety of lenses, which can be fitted with measuring lenses, enabling measurements at various resolutions. With the semipermeable mirror (functioning as a system separating the light), beam from the source is directed to the optical path of the system and focused by the lens at the measurement object (sample). Depending on the topography of sample, the light - upon reaching the object - is reflected from its surface in different directions. If the system has a surface texture diffusion properties, the light is scattered equally in all directions. In the case of specular reflection, beam is reflected in a specific one direction.

All rays reflected from the sample and reaching the lens are collected by a light sensor behind the lightsplitting system. Due to the small depth of field of view, only a small area of space is sharp. To perform full surface 
detection with full depth of field, the precision optical system moves relative to the table (displacement of one of these elements) along the vertical axis $z$ (in line with the optical axis). During this movement, sharp images are collected continuously, representing the inequalities and geometry of the measured surface [6]. This means that each region of the object has been reproduced from an image with the correct focus and resolution. The principle of such data collection is shown in fig. 2 .

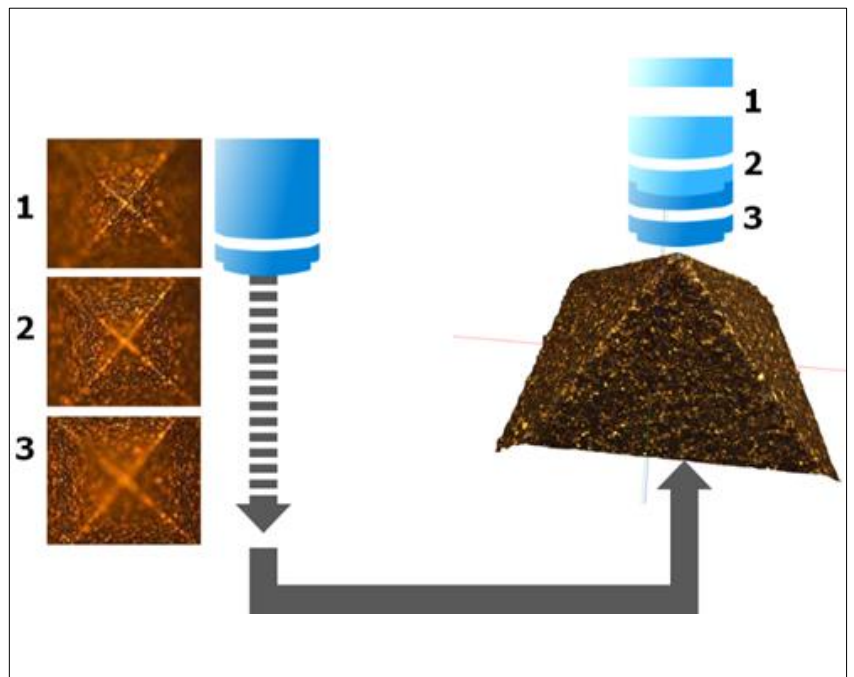

Fig. 2. Principle of continuous data collection from the surface

In accordance with the principles and theory of geometric optics, there is a direct relationship between the shape of the actual object and the shape of its focal plane, which allows the surface of the object (or its inequality) to be obtained from the focused image surface (FIS), that is, the focusing surface of the image formed by the set of points. The camera lens allows you to focus the light beam. It is schematically presented in fig. 3 .

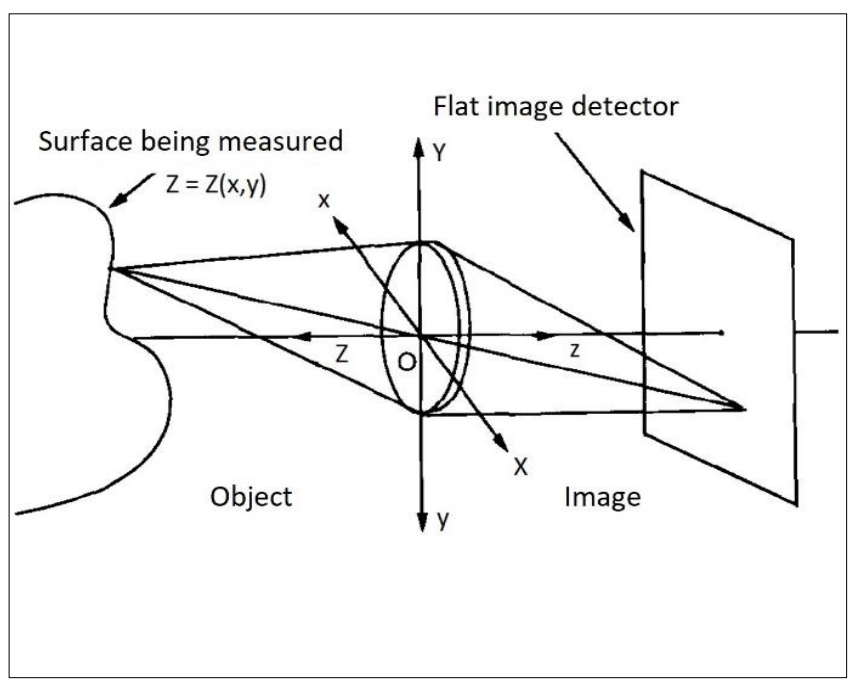

Fig. 3. Acquisition of the image in the technique of focal differentiation

The method used to obtain an image using focal differentiation is called the shape from focus (SFF) method. A special algorithm calculates the data collected by the sensor for three-dimensional information and the actual color of the object with full depth of field. This is achieved by analyzing the focus changes along the vertical axis. Combined with Real3D technology, it is possible to combine measurements from individual shots into one complete 3D data set.

\section{Measurement of tool geometry}

Measurement of surface features and micro-geometry by means of focal differentiation technology provides new research opportunities and allows new insights into cutting edge characterization problems, impossible to reach and unreachable in this field. Quality control is particularly important in the manufacture of tools, which are geared to measurements of rays, shifts, wear and micro-cracks. In particular, the possibility of performing identifiable measurements of geometry and roughness of various edges is an important advantage. The most important issues facing the manufacturers of cutting tools include the effects on the surface of the workpiece at the particular workpiece and shape of the cutting edge and the radius of its cutting. The sections, in which the measurements of radius and shape are made, are shown in fig. 4.

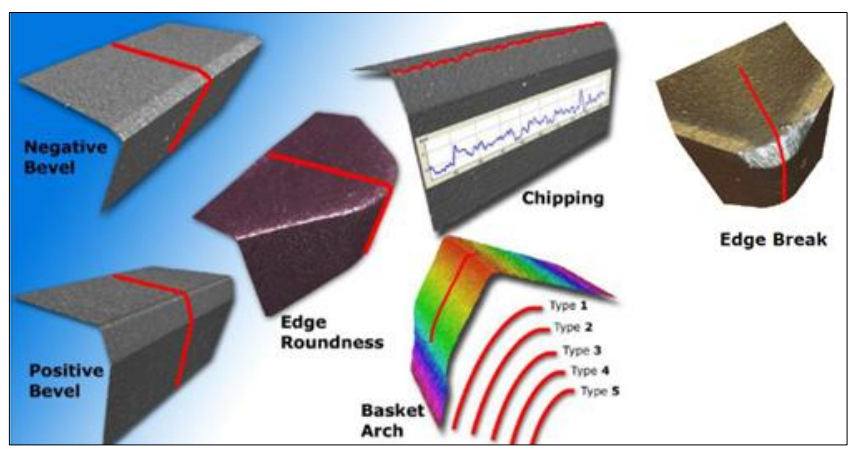

Fig. 4. Profiles, in which the measurements of features on the edge are made

The edges can be analyzed regardless of type, size, material or method of finishing the tool surface. The focal differentiation microscope enables the measurement tasks to be carried out with the radius of rounding of the cutting edges greater than $1 \mu \mathrm{m}$ and angles associated with the machining and tooling. The technology also guarantees the stability of results obtained even in production conditions (in the immediate vicinity of the technological machines). In this situation, the feedback loop is significantly reduced, and information about the correctness of the production or the interference reaches the production system within a single minute.

\section{Measurement of surface roughness of tools}

Typically, a special measuring system is used to identify the unevenness of the surface, allowing microtopography to be identified. In addition, measurements of the geometry at the macro-scale are carried out by means of a coordinate measuring machine or another device working in this technique (e.g. contour-meter). The focal differentiation microscope allows the combination of these two devices and the use of full operational functionality in one measurement system.

Fig. 5 shows an example of roughness profile with 2D parameters.

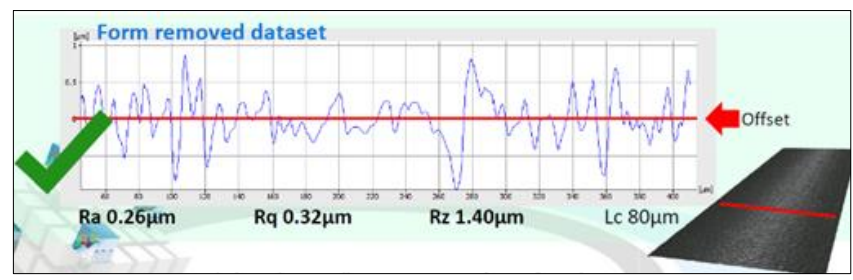

Fig. 5. Graph of the profile roughness obtained by the focal differentiation method 
As a result of this connection, quality control becomes easier and more efficient, as well as versatile in terms of generating the full-scale measurement reports. Inequalities can be analyzed in 2D, but also in 3D in accordance with ISO 25178 series.

\section{Spatial measurement of tools}

A rotary unit can be added as an auxiliary equipment to the measurement station using the focal differentiation technique. This allows to reproduce the full geometry of three-dimensional rotary tools - especially mills and drills - as well as irregularities on the rake and application surface.

An example of such a process is shown in fig. 6 .

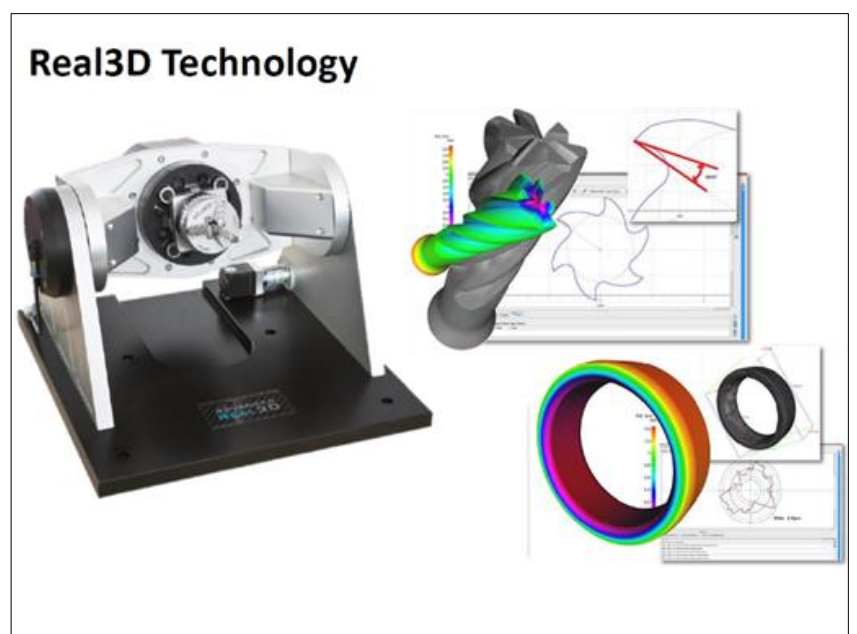

Fig. 6. Rotating unit allows full 3D scanning of tool geometries and rotary components

This way, it can be analyzed the effect of surface roughness on the manufacturing process, the object, and more broadly, on chip flow and product quality. An interesting option is the ability to compare the nominal and measured surface. To do this, a CAD file is loaded with the construction data of the cutting tool, and the actual surface is loaded. Such a comparison results in a color map of deviations from the CAD model. Another possible application of this technology is the reverse engineering of objects with unknown or incomplete geometry documentation.

\section{Measurement of wear}

A typical and common problem in machining tools is their wear and condition after a specified working time [7]. As shown in fig. 7, it is possible to scan a tool (object) before machining (new) and after it is finished (worn).

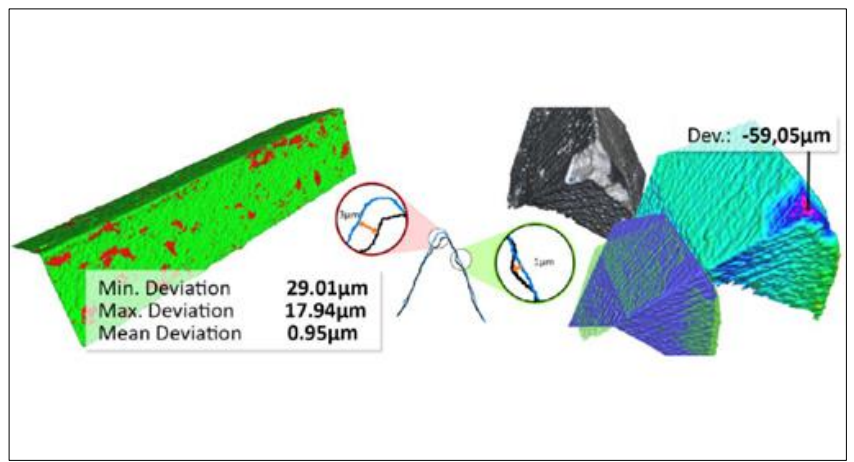

Fig. 7. Reconstruction of 3D image by focal differentiation technique
The special software module of the described focal differentiation microscope compares these two images and gives information about the amount of wear and its location on the individual components of the cutting tool. Also here, the effect of the work is a color map of deviations and deviation values at individual measurement points. A sample analysis is shown in fig. 8.

The wear analysis is at the same time the starting point for modifying the design features of the cutting tools or their manufacturing processes in such a way that they extend their life span in a view of the costs.

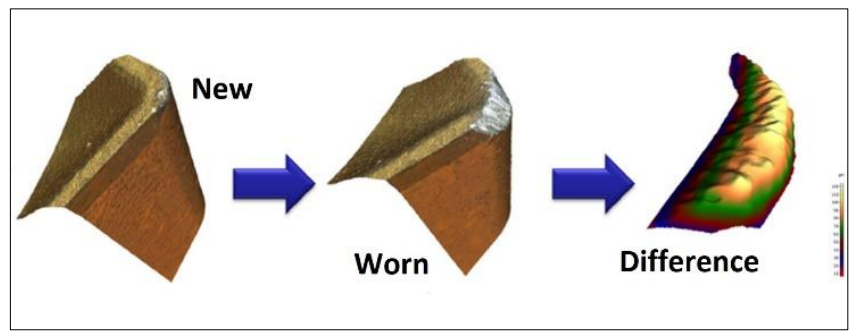

Fig. 8. Comparison of the new and worn tool fragment

\section{Conclusions}

The focal length differentiation microscope is used in one of the most interesting techniques for comprehensive analysis of data obtained from nano-, micro- and macroscales. It can be used in many branches of science and industry [8]. The benefits of this method also apply to the fact that, with focal differentiation, the projection of local slopes does not depend on the numerical aperture, which allows even very steep areas of the objects to be reproduced. Furthermore, the technique described can be accomplished in many different lighting methods, such as under the light incident by the lens or ring around a lens of several dozen segments, of which any number and orientation can be included. A polarizer that enhances the situation, when there are strong light reflections from very smooth surfaces (especially polished metal surfaces), is an additional option for working with different lighting.

\section{REFERENCES}

1. Danzl R., Helmli F., Scherer S. "Automatic measurement of calibration standards with arrays of hemi-spherical calottes". Proc. 11 th Int. Conf. on Metrology and Properties of Engineering Surfaces. Huddersfield, 2007, pages 41-46.

2. Leach R. "Optical Measurement of Surface Topography" ISBN: 978-3-642-12011-4 (Print) 978-3-642-12012-1 (Online).

3. Wieczorowski M. „Metrologia nierówności powierzchni - metody i systemy". Szczecin: ZAPOL, 2013.

4. Wieczorowski M. „Kierunki rozwoju metrologii nierówności powierzchni". Mechanik. 8-9 (2014): pages 467-479/600.

5. Subbarao M., Choi T. "Accurate recovery of three-dimensional shape from image focus". IEEE Trans. on Pattern Analysis and Machine Intelligence. 17 (1995): pages 266-274.

6. Danzl R., Helmli F., Scherer S. "Focus variation - a robust technology for high resolution optical 3D surface metrology". Strojniški vestnik - Journal of Mechanical Engineering. 57, 3 (2011): pages 245-256. DOI:10.5545/sv-jme.2010.175.

7. Danzl R., Helmli F. "Geometry and wear measurement of cutting tools". Int. Conf. on High Performance Cutting. Dublin. 1 (2008): pages 111-118.

8. Grossmann D., Hofer A., Brzozowski D., Wieczorowski M., Ziętkiewicz P. "Quality Assurance of Turbine Blades. Optical 3D metrology in the aerospace industry". DOI: 10.1714/mechanik.2015.12.561. 